\title{
The Social Dynamics of Social Science Research: Between Poetry and the Conveyer Belt
}

\author{
Emily Abbey \& Tania Zittoun
}

\begin{abstract}
This paper considers the semiotic organization of the research process in the social sciences. It offers a detailed analysis of the semiotic organization of a much used technique in the social sciences: the one-on-one non-directive interview. We consider how different signs might constrain the researcher's thoughts and actions within the ongoing processes of interview dialogue. We are especially interested in different semiotic representations that may constrain the researcher's understanding of his or her direct perception of phenomena: the researcher as a "poet" or as a "machine." It is suggested that these notions may differentially constrain the researcher's monitoring of the interaction with a participant, and that decisions in this monitoring process can have important implications for the ability of the interviewee to more fully express what it is he or she tries to communicate, and for the process of generating new knowledge. In conclusion, we suggest "poetic" and "mechanistic" approaches to the direct perception of phenomena, though distinct, may nonetheless be understood to complement one another.
\end{abstract}

Key words: Intersubjectivity, ruptures, interviewing, signs, machine, poetry

Please cite this article as:

Abbey, E. \& Zittoun, T. (2010). The social dynamics of social science research: Between poetry and the conveyer belt, Qualitative Studies, 1(1): 2-17.

\section{Research in the Social Sciences}

Humans use signs to organize their relations to the world, and an emerging field-cultural psychology-aims to better understand this process of 'meaning-making' (Bruner, 1990). Signs, which stand in for other things, function as organizers by constraining-in some way-the ongoing field of interaction, while also offering guiding suggestions for the future (Valsiner, 1998). Researchers in the field of cultural psychology have become interested in meaningmaking activities within an extraordinarily wide variety of domains of human activity. Yet there is one arena that remains somewhat understudied: their own research practice (see however Cornish, Zittoun \& Gillespie, 2007).

Signs are no less organizers of the dynamics of research in the social sciences than they are in any other domain of human psychological functioning, often with important consequences for all aspects of the methodological cycle (Valsiner, 1998; Valsiner \& van der Veer, 2000). Yet, this layer of organization often goes unnoticed by the very researchers who study the meaningmaking. For this reason, although discourse about research practice in psychology focuses on methods and techniques (Ginsburg, 1997; Gubrium \& Goldstein, 2001), the discursive construction of meaning (Grossen \& Salazar, 2006), and more rarely, ethics (Brinkmann \& Kvale, 2008) and the issues of participant's rights (e.g., informed consent and confidentiality), in this paper we explore the semiotic organization of the research process.

Interviewing in social sciences

There are numerous aspects of research methodology-understood as a cycle-(Branco \& Valsiner, 1997) which could be explored through our present focus. In this paper, we will narrow our focus specifically to the topic of one-on-one non-directive interviewing. One-to-one 
interviewing as a method is much used in the social sciences; much is written on its techniques, but it is less questioned as a practice and, nowadays, as an epistemological choice (Blanchet, 1991; Blanchet \& Gotman, 1992; Kohler Riessman, 1993; Kvale \& Brinkmann, 2008). In this paper, we do not question the use of this method. Rather, we focus on the semiotic organization of the interviewing process, considering different signs which might constrain the researcher's thoughts and actions within the ongoing processes of dialogue. We are especially interested in different notions of objectivity, and how these may constrain the researcher's monitoring of the sense-feeling stream of the interaction with a participant. We believe that different decisions in this monitoring process - whether to attend to ruptures in the feeling stream - have important implications for the ability of the interviewee to more fully express what it is he or she tries to communicate, and for the process of generating new knowledge. In this way, our focus here is both specific and general as we concentrate on a specific area, yet will conclude by suggesting how these ideas can be extended to other aspects of the research process.

\section{Intersubjectivity \& the Semiotic Configuration of Interviewing}

How to describe a research interview? Social sciences have developed rich understanding of situations of interaction and dialogue. They have given tools to describe a situation of interview as follows.

\section{A psychosocial description of the dialogue}

A research interview is a specific setting. Two participants who engage in that setting first have to make it exist as such. Through the dialogue and drawing on their experiences, representations, and expectations, they attempt to define the situation. A shared definition of the situation is part of establishing the dialogue. In therapeutic settings, for example, the main effort might precisely be to define what the conversation is about (Grossen, 1996, 2006). In turn, when the definition of the situation is not shared, misunderstanding can occur. Typically, an interviewee might believe that there is a "right" answer to the question asked by an interviewer, using a school-like definition of the situation (Grossen \& Perret-Clermont, 1994).

Once the definition is shared enough, a frame for the dialogue can be created. A frame is thus not something given; it is constructed through intersubjective dynamics. The frame enables a specific space, or field to emerge (Lewin, 1951). It sets a genre, mobilizes the participants' experiences of other dialogues, their understanding of implicit rules, their discursive, emotional and cognitive skills. The nature of the field is very often dependent on the clarity of the frame. For example, in a research interview the researcher makes explicit one rule, the fact that the data will be confidential. Thanks to the frame, each of the participants then knows what is allowed and expected: whether he will be judged or not, whether he can be informal or not, etc. In turn, participants can refer to the frame when the interaction becomes problematic; an interviewee can thus ask whether his discourse is relevant for the research.

The frame of a setting is itself mostly dependent on wider institutional demands and traditions, and traversed by various symbolic streams. Thus, an interview taking place in a university building is partly over-determined by this situational context, which also confers a specific status to the researcher as an "academic" which might be perceived "higher" in status than an interviewee who is a skilled worker. However, the frame can protect the situations from these various forces. Precisely, confidentiality might isolate the dialogue from the controlling presence of the institution.

Within such a framework, the discourse appears both enabled and canalized by many semiotic 
streams, and co-constructed by the participants. Important research has undertaken finegrained analysis of the progressive emergence of shared meaning. This has brought many researchers to see cognition or thinking as shared activity, with the problem of losing the person's internal activity (Mishler, 1996; Notterman, 2004; Salomon, 1993).

Our attempt is thus to bring back the intrapsychological processes at stake in an interview. In an interview, two persons are engaged in meaning making - both together, in interpersonal exchange, but also, on their own, in intrapsychological dialogue. Our proposition is to examine the relation between individual sense making and shared meaning in the ongoing flow of the conversation.

\section{Intrapsychological semiotic dynamics}

The same situation can be described from the perspective of either of the participants, engaged in meaning making. Each participant of an interview has a personal story, made of a large range of experiences and knowledge. The person has an experience from past dialogues, which gives him a certain number of expectations of what an interview is about, and how one communicates with another person. She might also have more formal skills, such as the mastery of narrative or argumentative styles, or interviewing skills, acquired in specific contexts of socialisation. Finally there is all the stuff that constitutes the person's life experience, opinions, thoughts, memories, wishes and desires, from which she can draw to nourish the content of a conversation.

One way of representing the dynamics through which people confer meaning to situations with others is given by the semiotic prism. A semiotic prism is the reunion of a classical psychosocial triangle, representing the interactions taking place between a person, an other and an object of discourse (Moscovici, 1984), and a semiotic triangle, showing how an idea time 1 and time 2 are always mediated by a sign under some form (after Vygotsky, see Vgotsky \& Luria, 1994, and Zittoun, Cornish, Gillespie \& Psaltis, 2007). In the following semiotic prism, we represent the person, an object of the world with the socially shared meaning it might have, an other person, and the sense that this object might have for the person.

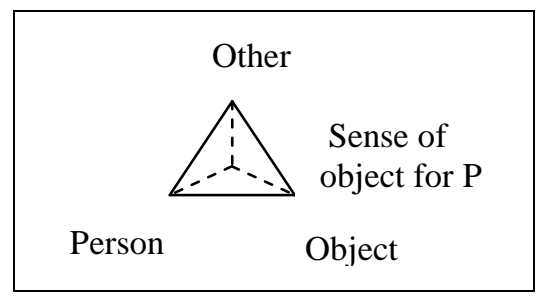

Figure 1 Semiotic prism

In our case, the object is any aspect of the situation of interviewing, mostly the co-constructed discourse, but also elements of the frame, non verbal communication, etc. The sense of the object is the echo or the resonance that the object has for the ongoing feeling life of the person, as well as her own conscious or unconscious memories, fantasies and wishes. Thus, at any moment of the interview, each person is engaged in an intrapsychological dialogue, where she examines what is currently being said, what it means in that particular frame and discursive exchange, and how it makes sense and feels for her.

For example, two persons might agree on the meaning that Titanic has (it is the story of a romance beyond class-barriers on a sinking boat). Yet both might have conferred very different 
senses to that film. One person might be an enthusiastic navigator, and for her the film evoked exciting images of fighting with powerful waves. The other person might be in the middle of a divorce procedure; the sense of the film for her would be that of a representation of the failure of passionate relationships. Thus, the two persons share the meaning of the film, but confer different senses to it.

Interpersonal dialogue semiotic dynamics: Emergence of meaning within the field

An interview situation puts in presence two persons engaged in meaning and sense making. In this interpersonal dialogue, two persons co-construct a discourse, that both persons usually expect to be co-understood, while each person also produces some sense to the discourse and the ongoing interaction in that particular setting. We could represent this by putting side by side two semiotic prisms, each engaged in their own dynamic, yet joined around the meaning of the ongoing co-produced discourse.

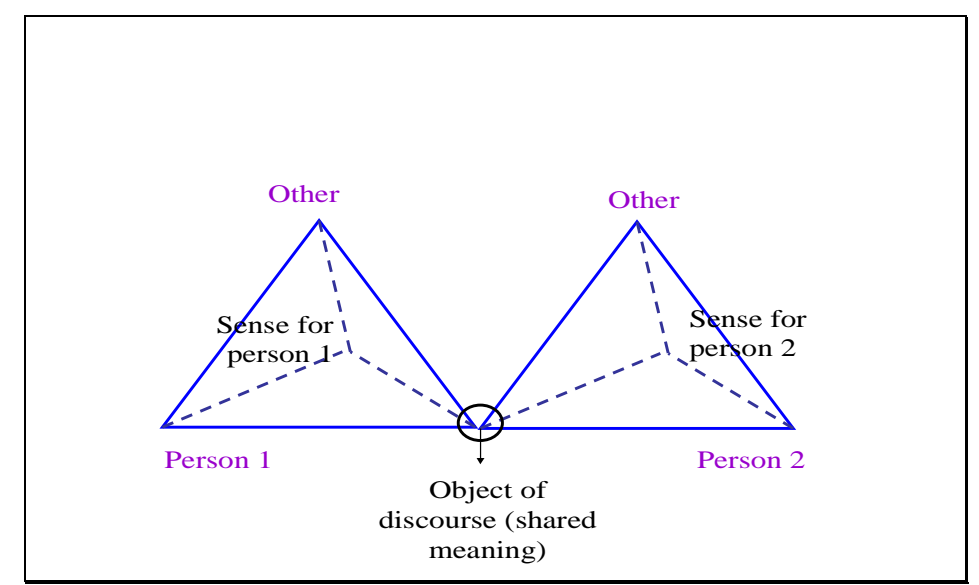

Figure 2 Semiotic prisms in intersubjective situation

In our example of two persons talking about Titanic, we can think that the conversation will feel differently for two persons that confer very different senses to the same object. Talking about the film, the navigator might engage her excitation and enthusiasm; the divorcee might rather feel sad. Yet these different feeling tones might well remain unobserved if the two persons concentrate on the meaning of their dialogue.

In effect, in a socially shared situation, two participants are generally expected to focus on the maintenance of a shared meaning. Personal sense is also usually expected to remain private. Our proposition here is that the research interview can, and should precisely give a full status to the ongoing gap between interpersonal meaning making and intrapersonal sense-making.

\section{Three semiotic streams}

To summarize our model and put these processes back in time, we can identify three (at least) intertwined streams of semiotic processes constantly occurring:

\section{STREAM 1: The meaning stream}

First, each person is engaged in the meaning-making of an interview, which is, diachronically, paving the way with signs to simply "understanding what the other is talking about", and reply to this etc. Both participants normally expect meaning to be shared to some extent. This is the overt stream of meaning. 
STREAM 2: The sense-feeling stream

Second, each person is engaged in sense making, which is directly following the participants' changing emotional experiences, constantly triggered by the presence and the discourse of the other, or any atmospheric reason. This stream is latent, and refers to how signs in the meaning stream "feel" for the person. It also involves further semiotic streams and their feeling tone.

\section{STREAM 3: The reflexive stream}

Third, each participant can also draw on various other signs to synchronically reflect on the ongoing evolving situation. The participants can use elements of the frame, of the definition of the situation, of their general expertise, to reflect on the whole field. More specifically, this is where the interviewer's expertise is becoming relevant. He or she might use signs to take some distance and raise higher-level, more general signs to reframe the whole field (this man says he did not eat meat, but, hoho, he is a vegetarian! Therefore probably left-wing etc.) Here professional skills are also engaged, and knowledge that might be used to trigger more discourse, hear within what is said, know when enough information about a topic is gathered, and so on.

These three streams of signs thus canalise and shape meaning which is constantly done and undone within the evolution of the interaction, the addition of new information, the changes of perspectives, the relational dynamics.

\section{Semiotic prisms and evolving fields of experiencing}

It is now possible to have a closer look at the ongoing evolution of these three streams of meaning, and at the interaction between interpersonal meaning making and intra-psychological sense-making. Within the field of the interview, the three streams of semiotic processes are constantly fusing, separating, interwoven and mingling with each other. But how can intrapsychological and inter-personal processes affect each other? To answer this question we need to speak about internalization - the processes whereby semiotic mediation in the shared reality become part of intrapsychological processes, and externalization - the processes through which intrapsychological processes take a shared semiotic form (Valsiner, 2007).

\section{From inter-to intrapsychological process}

In terms of the meaning-making process, the interviewee externalizes an idea through a verbal statement:

\section{“OJAJUDJHDLJ"}

which opens in the interviewer's mind a sub-field of possible meanings (e.g., what this person might say next, what her world is like, that is, the life-world of the other seen from the researcher's perspective):

She says "OJAJUDJHDLJ" $<>$ does this mean Y? X? Z?

This subfield of possible meanings constructs an ambivalence-the co-presence of forces of different degrees of attraction and repulsion (Lewin, 1936) ${ }^{1}$ occurring based on the conflict between the researcher's present relation to the world [she says "OJAJUDJHDLJ"] which offers

\footnotetext{
${ }^{1}$ Here we build on Lewin, who did not conceptualize the simultaneous combination of positive and negative valence-ambivalence.
} 
one idea, and the researcher's emerging subfield of possible meanings, all of which at that given moment are uncertain: [does this mean Y? X? Z?] (Abbey 2006; Zittoun, 2007). The interviewer immediately begins the process of trying to overcome this tension and uncertainty of meaning, formally in the interviewer's externalized response, for instance, "So you are saying Y..." which itself continues the process of his or her sense-making. So too, this externalization on the part of the interviewer: "So you are saying Y..." if internalized by the interviewee, inspires a subfield of possible meaning for her, instigating another tension and further progression of the interaction in an attempt to overcome this.

In a general sense, it is suggested here that ambivalence can be understood as a mechanism though which the interview develops, working on two interrelating levels:

Internalisation: Each externalized statement of one participant (the interviewee or interviewer), once internalized by the opposite, creates ambivalence for that person [she says OJAJUDJHDLJ $<$ does she mean $X Y Z$ ?] and inspires movement in her stream of subjective understanding as she attempts to overcome it: [she says OJAJUDJHDLJ $<$ does she mean X Y Z $>$ do you mean Y?].

Externalisation: This externalized statement [Do you mean Y?] once internalized, creates a reciprocal process of movement for that person, and can be understood to push the ongoing dialogue itself through time

\section{Fluctuations in ambivalence}

Within this general model, the level of ambivalence can fluctuate over time depending on the level of subjectively perceived uncertainty between one participant's internalized statement and its subjective reconfiguration. If the ambivalence is too weak meaning-making may stagnate ["we have nothing to talk about"] and at others it can grow so strong that sense-making becomes difficult ["what is she saying?!"] and the discussion, prematurely foreclosed. Broadly, a moderate level of ambivalence can be seen as ideal, wherein the interview proceeds in a start-stop manner for quite some time, where at each moment of exchange there is a possible rupture ["what does she mean?"], forming a tension strong enough to inspire further movement ["do you mean Y?"] and giving rise to the next meaning and further development.

\section{'Realness' of the Participant, Knowledge Construction \& the Sense-Feeling Stream}

One purpose of carrying out the research interview is to learn something from the participant. Yet, numerous issues complicate this otherwise straightforward goal, as suggested by the psychosocial analysis of the situation: meanings are also canalized by the power dynamics within the research setting, communication barriers such as language differences, as well as the general ambiguities of any ongoing communication depending upon how it is perceived (Buhler, 1928). One specific concern among these others will be our focus here. That is, within the interview, we only have "the meaning" of what the interviewee says, and this clearly cannot convey the entire richness of her ongoing experience-her phenomenological reality-at that given moment. As interviewers then, in some ways we constantly face the possibility of unintentionally overriding the participant's voice with our own, and therein missing the opportunity to learn, or develop new ideas.

Many interviewers will be sensitive to this dilemma from the start, and try as much as possible to avoid it. To this end they may, for instance, ask the interviewee if a question makes sense, or if there has been a miscommunication. The interviewer may often restate what the interviewee 
has said, to check whether one understands. Moreover, the interviewer may allow periods of silence when the interviewee does not immediately respond, so as to allow the interviewee's thoughts to unfold as they will. These tactics are useful, yet here, we build on those ideas, suggesting another possible-albeit indirect-option for being sensitive to the interviewee.

Ruptures within the sense-feeling stream

We propose the interviewer can increase his or her ability to know the other, to understand more deeply what this interviewee tries to communicate, exactly through a process which may seem a bit paradoxical, as the suggestion is for the interviewer to pay close attention to his or her own subjective experience. More specifically, we suggest the interviewer can better know the other by monitoring his or her own ongoing experience, and especially, his or her feeling stream. We are interested in those moments where we internalize what the participant says, forming some sense of it, and yet simultaneously, realize her statement nonetheless does not make sense at a deeper, more feeling-based level (see also Abbey, 2007). Such a moment can be interpreted loosely through the construct of rupture, as developed by Zittoun: "In a situation of rupture, changes are instances of disquieting experiences... which suddenly endanger customary ways of doing things, put at stake taken-for-granted routines and definitions. The obvious suddenly comes into question. In other words, there is an interruption of uncertainty in everyday experience..." (Zittoun, 2006, p. 6).

It is our sense that these moments of rupture within the feeling stream of our own ongoing experience may indeed signal exactly those moments when the participant is trying to communicate something which falls outside the boundaries of our sense of the world, that is, they signal instances where any assumed sense of intersubjectivity falters, at least momentarily. Yet, because these are the very moments when one may learn new things about the participant, potentially leading to new insights, we can call these ruptures in our own ongoing feeling stream heuristic ruptures. Of course, such ruptures in understanding may not mark such moments. But rather than treat such moments as annoyances to be moved beyond quickly, we here suggest the loss of mutuality may signal a need for deeper focusing in just that place, focusing on that ambiguity, thus avoiding as much as possible overriding her voice with our own.

Sensing intersubjective ruptures: Monitoring the sense-feeling stream

Functionally, how can such monitoring for intrasubjective and intersubjective ruptures be accomplished? For this we need to come back to ambivalences. As suggested above, we here consider three semiotic streams (meaning stream, sense-feeling stream, reflexive stream); ambivalence can appear within any of these streams, but also as these streams seem to appear contradictory or divergent. We here focus on a tension within the sense-feeling stream, or between having some idea of what the person said, yet sensing at a latent level that it does not make sense. This ambivalence-like all others-is, to some degree, present during an ongoing interview as no one ever feels they understand everything about what the other party is saying. Nonetheless, we here are especially interested in those moments where the tension grows strong. It may be at this moment that the ambivalence becomes explicitly noted as a rupture. Thus, functionally, we suggest to be aware of intersubjective rupture by way of reflectively monitoring the sense-feeling stream 


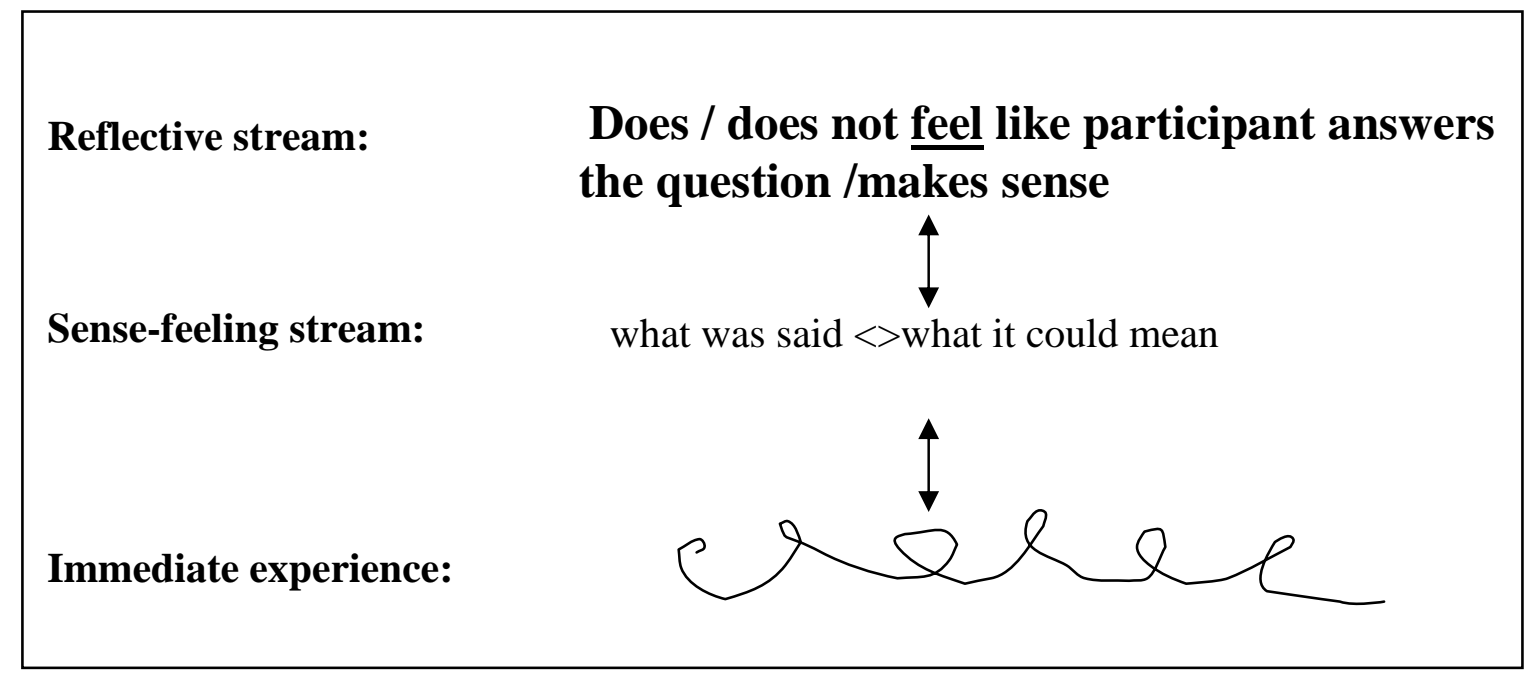

Figure 3: Reflective monitoring of the sense-feeling stream

Semiotic guiding of the interview exchange

We suggest that the monitoring of the sense-feeling stream can occur through a reflective semiotic stream, drawing on various other semiotic devices to synchronically reflect on the ongoing evolving situation. The specific nature of these semiotic devices or mediators is critical to our point here: what should happen when one senses, "While we are still talking about the same thing, it feels as if we are not." This basic scenario can be represented abstractly as follows.

Regulators for reflective stream: Two options

A) Keep going (possible rationalization: It is simply a 'bad' question or phrasing). In this case, the professional reason wants us to be neutral and objective: avoid emotion, and if they are aroused so to be noticed, let them fade out.

B) Stop and focus here! In contrast to option A, in this latter case, the professional reason wants us to consider a different quality of connection to feelings, and to the ongoing interaction itself.

\section{Meta-level semiotic organizer of monitoring}

\section{Reflective monitoring of} sense-feeling stream:

Immediate experience:

Sense-feeling stream:

\section{Keep going / Stop and focus here}

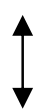

Does / does not seem to answer the question

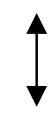

what was said $<>$ what it could mean

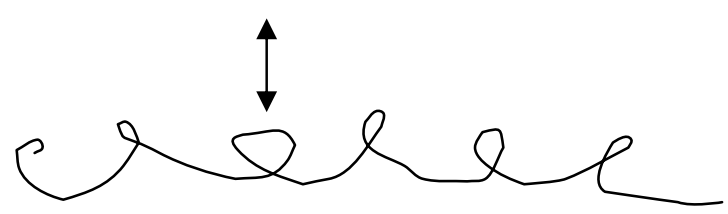


Figure 4: Meta-level organizing of how sense-feeling stream in monitored

On the necessity of monitoring semiotic streams

We thus propose to consider the movement enabled by a "stop and focus here" semiotic mediator as a core move in a research interview. It is not only fundamental for epistemological reasons, as a tool to get access to the other's stream of experience and meaning-making. It is also fundamental for ethical reasons, as the researcher who creates the interview setting has the responsibility to not let "fall" the other out of the field of the shared understanding (Abbey, 2002). But how does a researcher develop such an ability to identify ruptures, and to distance herself from the stream of meaning thanks to a "stop and focus here" tool? As any other distancing tool, it might have three main origins. It might simply come from the researcher's retrospective analysis: the experience of ruptures called the researchers attention on the phenomenon and from that new perspective, the awareness on these situations emerges (Mead, 1932). This might also have emerged through dialogue with other researchers, as dialogue can imply a change of perspective. Finally, it might also be the result of the researcher's reflection and location within a tradition of theories and meta-theoretical orientations, as we will now examine.

\section{Illustration}

The following is a snippet of an interview conducted by the first author, used to illustrate the above outlined process of rupture in the sense-feeling stream, monitoring for those ruptures, and the novel view of the participant's subjective experience that may be gleaned from such efforts. The participant is a 20-year-old woman, pseudonym Amanda. During the interview, Amanda is recounting how she and her family arrived in the United States after escaping from the anarchistic conditions that had existed in her native country-Albania-after the fall of the Communist government in 1990. At the time of the interview, she and her family had been living in America for four years. In her own words, she describes the situation she and her family left in Albania as follows:

And especially when I left here, it was in $1997 \ldots$ the country was in total chaos. There was no government. The government was overthrown. For a while there was complete anarchy. Everybody [...] had arms, they had to defend themselves. [...] Because [...] during that time $[\ldots]$ there was no police, $[\ldots]$ people were doing whatever they wanted to do. And you know, $[\ldots]$ rape usually $[\ldots]$ was very common, and schools were closed because a lot of parents, you know, wouldn't send, especially girls to school, because they had [...] absolutely no protection. And, you know, schools were closed for four months during that time. And $[\ldots]$ you're at home, you can't go out for four months. It was $[\ldots]$ isolation, especially for girls my age.

As Amanda describes the high prevalence of women who were raped during the anarchistic period she had lived through in Albania, I-the interviewer-was interested to know how she made sense of these horrific events, and why women had suffered so much more than men during this time. I understood the discrepancy in suffering through a sort of feminist lens, seeing these rapes and maltreatment of females in particular as stemming from a broader, societal level pattern of discrimination based on the belief that women are inferior to men. I asked:

Q: What... I was wondering, um, sort of about that. Like, for men, were there... I was wondering, you know, were women particular targets [...] or... 
Amanda replies:

A: Well, women are... have always been more vulnerable. And especially in societies like Albania that have, you know, sort of had in their culture that women are, you know, probably not inferior but, you know, less powerful towards men. Especially when it comes to the physical, to the physical side. But you know, they can't defend themselves as men would, or you know, they don't have the physical strength as men would. So, you know, that sort of, um, nurtures the whole feeling of superiority, I mean indirectly... even if it not direct...

In this initial response, Amanda seems to begin with comments that are ostensibly consistent with my own understanding of gender inequality as she links difference of treatment between the sexes to a societal level pattern of discrimination. She says, "And especially in societies like Albania that have, you know, sort of had in their culture that women are, you know, probably not inferior but, you know, less powerful towards men." However, in the next sentence of Amanda's response to me, a feeling of rupture in the sense-feeling stream begins to occur. She says, "Especially when it comes to the physical, to the physical side. But you know, they can't defend themselves as men would, or you know, they don't have the physical strength as men would..." By saying this, Amanda seems to emphasize that much of the inequality between men and women's treatment is rooted in discrepancies in physical size and strength. Her comment created a rupture in the sense feeling stream because, from my perspective, such a differential in physical strength is a characteristic of an inequality between men and women that would always exist--even in a society where the dominant belief was in equality between the sexes. I felt as if Amanda was downplaying societal level inequalities between the genders that-from my perspective-heavily maintained the environment where excessive violence, and acts like rape could be differently perpetrated against women. Thus, at the time, Amanda's response made sense in terms of stream 1, that is, I could understand what she was saying, but in terms of stream 2, there was a definite rupture in the sense-feeling of the moment.

It is at this point in the interview where the semiotic mediation of the ongoing interaction becomes critical. Using stream 3, at this moment I had two choices-either assume the question had been poorly worded and continue, or to stop and focus, trying to better understand. I chose this as a moment not to ignore, but to "stop and focus." Practically, this resulted in my asking Amanda another question, one in which the aim was to clarify and understand better Amanda's sense of the causes of women's disproportionate level of suffering, especially rape. Did she think about societal level patterns of discrimination, or did she believe that physical differences in size were primarily to blame for what she and other women had experienced during the war? I ask:

Q: And it... I was wondering, are there other ways you think in Albania that women are thought of to be quote-unquote "less strong" than men? Or is it just something that is about, um, their physical abilities?

Amanda responds:

A: No, it's just about how, like, society cultivates the whole feeling about it. Women are okay with it, that they're... they're viewed that way. I mean in Europe they give a... a more emphasis on femininity and, like, you know, being feminine. Not too muscular 
and that kind of thing. It depends. You know, though. It'll... it doesn't really matter how much... how the society... well, it doesn't really matter how you put it, like, you know, they're physically stronger, or mentally, or that kind of thing. It all depends how a society chooses to view. And then women have... have just accepted it for the... sometimes they didn't have a choice, and sometimes, you know, they were okay with it. So...

Again, the sense of rupture in the sense-feeling stream could be felt. After all, Amanda didn't seem to be negating my views in a broad sense, for in both of her answers she spoke of gender inequality as being based at the level of societal beliefs and practices. Yet in both her answers she nonetheless seemed to be purposely de-emphasizing this fact-and what to me was the central issue. In this second response, her primary point seemed to be that European women understand their femininity differently than they do in America. While I understood what she was saying, I didn't see what it had to do with the fact that women were being raped. Certainly Amanda was not saying that by being more comfortable with their femininity, these women also accepted the phenomenon of rape!

\section{Preserving the 'real' Amanda}

By highlighting these moments of rupture in the sense-feeling stream, it started to become clear that Amanda was not trying to avoid my question, nor did she necessarily share different views than I in terms of the roots of the disproportionate amount of suffering females had experienced, as compared to males. At the same time, she was, however, trying to communicate two additional points. First, it wasn't that Amanda didn't acknowledge the societal-level basis for discrimination against women, but rather, in her lived experience, the physical inequalities between the sexes had been far more salient. The act of rape is, of course, at a basic level, one person's physical will overpowering another's. For me, having never had the immediate contact with rape that Amanda had experienced in her native country, societal-level explanations were primary. By contrast, for Amanda, a societal-level basis for inequality was of secondary importance to physical strength.

Second, and in relation to her second response, Amanda seemed to be resisting defining her own female identity through to my own "American-feminist-female identity." Perhaps, it wasn't that Amanda and I disagreed that the rape of women is wrong, and that its prevalence and acceptance is linked to a societal level reinforcement of gender inequality, but rather, that Amanda was trying to communicate that the models of female identity she constructed her resistance from were different from mine. In some ways she was perhaps trying to point out that many feminists in the United States may actively resist by shunning traditional semiotic indicators of femininity, such as cosmetic use, long hair, wearing skirts, etc. By contrast, Amanda in no way wanted to adopt this sense of herself. In essence, to fully answer my question, and to determine her own meaning, Amanda needed to resist me at the same time that she resisted societal norms in her native Albania.

\section{Guiding of the Interview Process: 'Artists' \& 'Machines'}

Thus far we have considered the interview setting as framed within a semiotic and fieldtheoretic conceptualization of the interview setting, and considered the importance of not 'losing' the 'real' participant, because it is from her that we learn, and that new ideas may emerge. We have also discussed the importance of monitoring our own-as interviewerssense-feeling or latent aspects of experience as a means to try and preserve that real person. We finally have pointed out the role of meta-level signs "keep going/stop and focus here" as 
guiding that all important monitoring of the feeling sense of stream 2, and in turn, possible loss of intersubjectivity.

In this third section of the paper, we turn more broadly to the fact that the meta-level signs that guide the researcher in his or her moment-to-moment movements during the research interview do not arise from nowhere. Such guiding can be understood as reflecting still higher, more abstract discourses covering different models of knowledge construction, and especially, the researcher's direct perception of phenomena. It is in this section that we will explore briefly the notions we believe guide these decisions, and their implications for the specific aspect of the interview research process on which we here focus.

\section{Theorizing the researcher's felt rupture}

Our attempt to give a full status to the researcher's experience of rupture within his sense and feeling within an interview is not a romantic stance for more empathy in research. On the contrary, it follows a theoretical and epistemological reflection about the specificities of a research situation involving two persons or more, a characteristic of social sciences. Some long, yet marginalized traditions of research, have attempted to name and theorize what we have called a "stop and focus there" semiotic mediator. Here we present two current reflections. In recent phenomenological reflection, authors have developed techniques to create the special sort of suspension of attention demanded by the "stop and focus here". It requires notably a moment of suspension, and a redirection of attention from the outside, shared social reality, to the internal sense-making. Although this redirection corresponds to what we describe, in this tradition the authors are interested in situations where the interviewer asks the interviewee to "stop and focus" on some experience he or she is mentioning; the researcher is not interested in his own stream of sense-making in the experience of interview (Depraz, Varela \& Vermersch, 2002).

The question also been addressed by psychoanalysis under the term of "counter-transference". Counter-transference is the feeling-sense provoked within the psychoanalyst by the interpersonal situation, including the shared discourse with its ambivalences, and his perception of the variations of the feeling-sense stream of the patient. Some psychoanalysts consider ruptures in their counter-transference as major technical tools. They indeed try to analyze the change in their personal stream of sense-feeling, and on this basis propose an interpretation of what is going on in the patient. The condition for such use of countertransference is the fact that the analyst has himself acquired a strong personal insight through psychoanalysis, enabling him to distinguish in his or her reaction, the part of his personal life and echoes, and the part due to the variation in the other (Neyraut, 2004; Quinodoz, 2003; Rosenbloom, 1998; Winnicott, 1958).

The research interview differs from these two situations as follows: the researcher is not trying to provoke a state of suspension in the other, he is using naturally occurring ruptures, like the psychoanalyst; yet unlike the latter, he does not use this rupture to make hypotheses about the sense-feeling making of the other. Rather, he uses the "stop and focus" semiotic mediator to ask a new question to the interviewee and thus reorient the shared field of experience.

Identifying the researcher: Poet or machine?

Beyond these differences, the phenomenological, the psychoanalytical, and our semiotic positions obey the same principle: the attempt to theorize the perspective of the researcher as part of the meaning being created within the experience of a dialogue (see also Devereux, 1967; 
Fogel, 2006). Broadly speaking, such a focus itself has-more profoundly-been understood to correspond to one same meta-theoretical position, which is usually opposed to "mainstream" psychology. Within mainstream psychology, there is a common emphasis, suggesting that objectivity is indeed made possible in part through the researcher remaining more or less separate from the research process, not coloring the experience with his or her thoughts, feelings or actions any more than is necessary. Such a focus is, in many senses 'mechanistic' insofar as researchers are aiming to minimize any differences between them, as one who aims to avoid or move quickly past ambiguities that may arise within the process, and who aims to simply carry out the data collection and analytical duties with as much interpersonal consistency as possible.

We here speak about something of an 'alternative to the mainstream', broadly speaking, reflecting more of a 'personal-perspectival' approach to understanding phenomena (Valsiner, 1998, p. 293). It is an orientation that departs from a sense of the researcher as a totally autonomous aspect of the research process, and instead emphasizes the researcher act more as a poet than a machine, that is, as one who is personally connected to the research process, one who tolerates the ambiguities within it-and even focuses on them, insofar as they may signal important moments. One who understands his or her personal and unique insights as valuable tools in knowledge construction.

\section{General Conclusions}

In this paper we have explored the semiotic organization of the research process in the social sciences. To do this, we have concentrated on a much used aspect of that process: the semidirective or non-directive interview. Looking at the interview, we have focused on those moments where the researcher experiences a rupture in his or her ongoing latent or feeling sense of the participant's comments. We have suggested that these may be critical moments in the process of knowledge construction, but noticing and paying attention to these moments does not simply happen, rather, it is regulated by higher-order signs, whose meaning reflectspotentially - the researcher's immediate theoretical tradition, as well as highly abstract notions of knowledge construction and the researcher's relation to phenomena in the social sciences, which we have for the sake of discussion termed the "poet" or the "machine".

In so making this contrast, it is not our intention to create or support yet another bifurcation in psychology. Moreover, in conclusion we would like to point out that even what we here term 'poetic' itself is only made possible through some rather 'mechanistic' processes. In what we have here offered, we certainly promote some 'mechanistic' aspects of the researcher's relation to phenomena-though we would caution against ignoring the changes in the feeling stream, as a 'mechanistic' approach to phenomena traditionally would. We suggest the creation and maintenance of the frame, and importantly, the techniques for mediation to be used for reflective distancing on the sense-feeling stream (or stream 2). In our understanding, it is only through these functional/mechanistic means-especially the decision to attend to ruptures within the feeling sense of stream 2-that we theoretically and experientially assume more of a 'poetic' relation to the phenomenon in question. By using these techniques, we increase our connection to the process, hopefully better understand it, and become part of the process through which new ideas do emerge.

\section{Acknowledgments}

A preliminary version of this paper was presented at the International Society for Theoretical Psychology conference, Toronto, June 18, 2007. 


\section{References}

Abbey, E. (2002). Relating Bakhtin to a feminist researcher: Resisting the loss of self determination. Presented at the conference "Women in Dialogue with Philosophy", Boston College, Boston, Massachusetts, April 5.

Abbey, E. (2007). The boundary between you and me: Semiotic architecture of thinking and feeling the other. In L. Simao \& J. Valsiner, (Eds.), Otherness in Question: Development of the Self. Greenwich: Info Age.

Blanchet, A. \& Gotman, A. (1992). L'enquête et ses méthodes : l'entretien. Paris: Nathan Université.

Blanchet, A. (1991), Dire et faire dire, l'entretien, Paris: Armand Colin.

Branco, A. U. \& Valsiner, J. (1997). Changing methodologies: A co-constructivist study of goal orientations in social interactions. Psychology \& Developing Societies, 9(1), 35-64.

Brinkmann, S. \& Kvale, S. (2008). Ethics in qualitative psychological research. In C. Willig \& W. Stainton-Rogers (Eds.) The SAGE Handbook of Qualitative Research in Psychology. London: Sage.

Bruner, J. S. (1990). Acts of meaning. Cambridge: Harvard University Press.

Bühler, K. (1928). Die Symbolik der Sprache. Kant-Studien, 33, 405-409.

Cornish, F., Zittoun, T. \& Gillespie, A. (2007). A cultural psychological reflection on collaborative research. Conference Essay: ESF Exploratory Workshop on Collaborative Case Studies for a European Cultural Psychology [37 paragraphs]. Forum Qualitative Sozialforschung / Forum: Qualitative Social Research, 8(3), Art. 21, http://www.qualitativeresearch.net/fqs-texte/3-07/07-3-21-e.htm.

Depraz, N, Varela, F. \& Vermersch, P. (Eds). (2002). On Becoming Aware. Amsterdam/Philadeplpia: John Benjamins.

Devereux, G. (1967). From anxiety to method in the behavioral sciences. The Hague: Mouton \& Co.

Fogel, A. (2006). Dynamic systems research in interindividual communication: The transformation of meaning-making. Journal of Developmental Processes, 1, 7-28.

Ginsburg, H. P. (1997). Entering the Child's Mind: The Clinical Interview in Psychological Research and Practice. Cambridge: Cambridge University press.

Grossen, M. (1996). Counselling and gate-keeping: Definition of the problem and the situation in a first therapeutic interview. Text, 16(2): 161-198.

Grossen, M. (2006). Analyse de la demande et construction du "problème" dans un premier entretien clinique. In M. Grossen \& A Salazar Orvig (Eds.). L'entretien clinique en pratiques. 
Analyse des interactions verbales d'un genre hétérogène. Paris: Belin.

Grossen, M., \& Perret-Clermont, A. (1994). Psycho-social perspective on cognitive development: Construction of adult-child intersubjectivity in logic tasks. In R. Maier \& W. de Graaf (Eds.), Sociogenesis reexamined. New York: Springer.

Grossen, M., \& Salazar Orvig, A. (1996). L'entretien clinique en pratiques: analyse des interactions verbales d'un genre hétérogène. Paris: Belin.

Gubrium J. F. \& Goldstein J. A. (2001). Handbook of interview research. London: Sage

Kohler Riessman, C. (1993). Narrative Analysis. Qualitative Research Methods, vol. 30. Newsbury Park: Sage Publications.

Kvale, S., \& Brinkmann, S. (2008). InterViews: Learning the Craft of Qualitative Research Interviewing (2nd ed.). London: Sage.

Lewin, K. (1936). Principles of Topological Psychology. New York: McGraw-Hill Book Company, Inc.

Lewin, K. (1951). Field theory in social science. New York: Harper \& Brothers.

Mead, G. H. (1932). The philosophy of the present. London: The open court company. Available online at: http://www.archive.org/details/philosophyofthep032111mbp

Mishler, E. (1996). Missing persons: Recovering developmental stories/histories. In R. Jessor, A. Colby \& R.A. Shweder (Eds.) Ethnography and Human Development: Context and Meaning in Social Inquiry. Chicago: Chicago University Press.

Moscovici, S. (1984/2003). Introduction. Le domaine de la psychologie sociale. In S. Moscovici (Ed.). Psychologie sociale. Paris: Presses universitaires de France.

Neyraut, M. (1974), Le transfert, étude psychanalytique. Paris: Presses Univrsitaires de France.

Notterman, J. M. (2004). Persistent conceptual issues in psychology. A selective update. Theory \& Psychology, 14 (2), 239-260.

Quinodoz, D. (2003). Words that Touch: A Psychoanalyst Learns to Speak. London: Karnac.

Rosenbloom, S. (1998). The complexities and pitfalls of working with the countertransference .Psychoanalytic Quarterly, 67(2): 256-275.

Salomon, G. (1993). No distribution without individuals' cognition: A dynamic interactional view. In G. Salomon (Ed.). Distributed Cognitions. Psychological and Educational Considerations. Cambridge: Cambridge University Press.

Valsiner, J. \& van der Veer, R. (2000) The Social Mind. Cambridge: Cambridge University Press. Valsiner, J. (1998). The Guided Mind. Cambridge, MA: Harvard University Press. 
Valsiner, J. (2007). Culture in Minds and Societies. Foundations of Cultural Psychology. New Delhi: Sage.

Vermersch, P. (1999). Introspection as practice. Journal of Consciousness Studies, 6, 2-3, 17-42.

Vygotsky, L. S., \& Luria, A. (1994). Tool and symbol in child development. In R. Van de Veer \& J. Valsiner (Eds.), The Vygotsky Reader. Oxford: Blackwell.

Winnicott, D. W. (1958). Collected Papers. Through Pediatrics to Psychoanalysis: New York: Basic Books.

Zittoun, T. (2006). Transitions: Development through Symbolic Resources. InfoAge.

Zittoun, T., Cornish, F., Gillespie, A. \& Psaltis, C. (2007). The metaphor of the triangle in theories of human development, Human Development, 50, 208-229.

\section{Authors}

Emily Abbey is an Assistant Professor in the Department of Psychology at Ramapo College of New Jersey. Working from a developmental orientation and a cultural perspective, she is generally curious about the semiotic organization of human lives, and the relationship between poetry and psychology. Recently, she has published in the journals Culture \& Psychology, Estudios de Psicologia, and is co-editor of a volume on microgenetic approaches titled, Innovating Genesis: Microgenesis and the Constructive Mind in Action (with Rainer Diriwächter, InfoAge). Email: eabbey@ramapo.edu

Tania Zittoun is Professor of Education at the University of Neuchâtel, Switzerland. She is interested in people's changes through their interactions with symbolic objects and with other people. She is associate editor of Culture \& Psychology, and has recently published in Human Development and the International Journal for Psychological and Behavioral Science. She is the author of the book Transitions: development through symbolic resources, and of two other books on the institutional and semiotic mediations of youth and adult transitions. Email: Tania.Zittoun@unine.ch 